\title{
Research of Geometric Accuracy of Circular Holes Machined by Wire EDM Technology
}

\author{
L’uboslav STRAKA*, Ján PITEL', Peter MICHALÍK
}

\begin{abstract}
The geometric accuracy of the machined surface after WEDM can generally be understood as complying with the requirements of shape, position, orientation and runout accuracy. Its level is usually quantified by the respective deviations from the nominal value. Even though WEDM technology is one of the most accurate finishing machining technologies, when manufacturing curved shapes or rotational surfaces there are certain deviations from the desired geometric shape or dimension. Therefore, the aim of the applied experimental research was to contribute to the database of existing knowledge, which can clearly define the extent of the influence for a specific combination of workpiece material EN S355J0 and wire electrode material parameters CuZn37 through a clear formulation of individual laws in relation to geometric precision of curved surfaces after WEDM. The subsequent aim was, based on the analysis of the obtained results, to determine the primary causes of the occurrence of geometric deviations, and to propose recommendations for their elimination.
\end{abstract}

Keywords: circularity; curved surfaces; geometric accuracy; quality; Wire Electrical Discharge Machining (WEDM)

\section{INTRODUCTION}

The surface of most machined surfaces is made up of various geometrical elements. Since a variety of factors are present during machining, it is not always possible to achieve the ideal, i.e. the prescribed surface shape. The areas then have smaller or larger deviations from the ideal geometric shape. If only one shape element is considered then its deviation from the ideal geometric shape according to international ISO standards is classified as a deviation of the shape. At the same time, in practice we often encounter the requirement of a particular bond that is given between the base and a certain shape element. For example, a certain part should be parallel or perpendicular to another part, or the two parts together make a certain angle and so on. Because WEDM is one of the finishing machining technologies with a high quality of machined surface [1], even a small geometric deviation from the desired shape, position, orientation or runout [2] can have a significant impact on the functionality of the finished component. This is also evidenced in the research by Ali et al., Firouzabadi et al. and Islam et al. [3-5]. They emphasize the geometrical accuracy of the WEDM machined surfaces, especially in terms of dimensions. When increasing the geometrical precision of the machined surface, the research was oriented mainly on the optimization of the wire electrode feed rate. This was in particular the main focus of research by Raksiri et al., Sanchez et al. and Yan et al. [6-8]. In their works they describe some improvement in the geometrical precision of the machined surface by reducing the wire electrode feed rate. However, it should be noted that a substantial reduction in the wire electrode feed rate of the electrode leads to a significant improvement in the number of geometric precision indicators of the machined surface. On the other hand, there is a significant fall in manufacturing productivity [9] and thus a low economic efficiency of the electro-erosion process [10]. Some researchers have on the other hand performed a parametric study of the geometric inaccuracy caused by the wire electrode itself. At the same time, they attempted to describe these patterns in mathematical terms. Puri et al. [11] describe part of these results in their studies, where they focused on the dependence of geometric accuracy of the machined steel surface with WEDM from the wire electrode feed rate. Simulation was performed using the Taguchi method. However, all of these studies were oriented on flat surfaces.

It can be seen from this that the geometrical inaccuracy of not only flat surfaces but also of the curved surfaces after WEDM is substantially influenced by the precision of the wire electrode feed. This is affected on the one hand by the hardware and on the other hand by the software precision of wire feed. Therefore, the experimental research was focused primarily on contributing to the knowledge base through a clear formulation of the particular laws in relation to the geometric accuracy of curved surfaces after WEDM. This includes in particular the identification of geometric deviations of the curved surfaces of the circular cross section of steel EN S355J0 after WEDM with $\mathrm{CuZn} 37$ wire electrode $\phi_{\mathrm{E}}=0.25 \mathrm{~mm}$.

\section{THE FUNDAMENTALS OF GEOMETRIC DEVIATIONS OF MACHINED SURFACE AFTER WEDM}

As mentioned earlier in the introduction, despite the high quality of the work area after WEDM, there are some deficiencies. One of the major deficiencies is the geometric deviation of the machined surface from the required dimension or shape. In case of maximum deviation of the dimension or shape we recognize the maximum distance $\Delta$ point of the actual work area achieved from the desired "nominal" area of the envelope surface. The tolerance field of geometric deviations thus represents the spatially bounded area between the nominal region and the tolerated region.

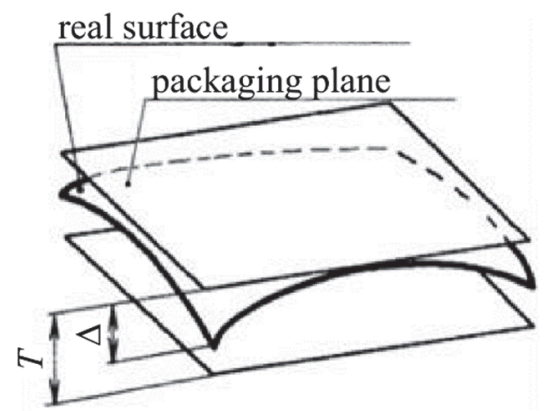

Figure 1 Tolerance field $T$ of geometric deviations of shape $\Delta$ of real machined surface from the nominal 
These regions are separated apart by a length equal to the prescribed tolerance $T$ (Fig. 1). It follows that for the production of high-quality products, it is crucial that the actual "real" machined area be in the section between the nominal and the tolerated area.

A separate group of geometric shape deviations includes circular deviations. The circularity of a particular profile is considered to be correct if the difference in radii of the two concentric circles between which any point of the actual profile is equal to or less than the tolerance value $T$. The centre of the concentric circles and their radii must be chosen such that the difference of their radii is as small as possible (Fig. 2).

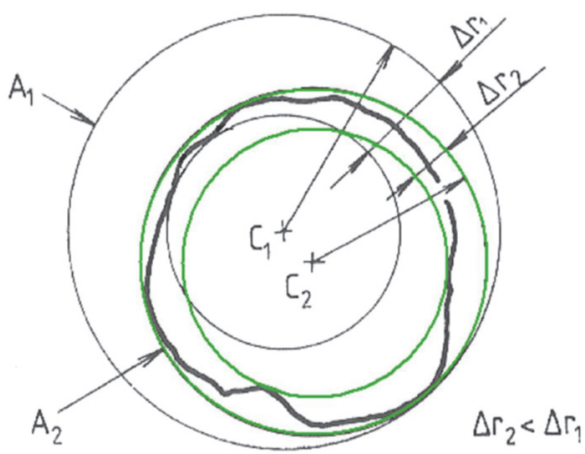

Figure 2 Basic parameters of the geometric deviations of circularity of the machined area prescribed by STN EN ISO 1101: 2013-12: $A_{1}$ - is the position of concentric circles with centre in $C_{1}, A_{2}$ - is the position of concentric circles with centre in $C_{2}, \Delta r_{1}, \Delta r_{2}$ - the particular radial distances of the circles.

The correct position of the concentric circles according to Fig. 2 is denoted as $A_{2}$ with center in $C_{2}$. Then, the maximum allowable distance $\Delta r_{2}$ in the given cross section is represented by two concentric circles [12]. Their maximum radial distance is equal to the maximum allowable value generally referred to as the tolerance $T$. The real dimension of the machined surface in any cross section of the cylindrical or conical surfaces must therefore be between these two concentric circles. Otherwise we consider it to be a poor workpiece [13]. Formation of geometric deviations of shape [14] of the actual from the nominal "required" machined area after WEDM is dependent on several factors [15]. This is in particular the precision of the used CNC machine tool [16], the type of electrode [17], the workpiece material $[18,19]$ as well as the adjustment of the process $[20,21]$ and the technological parameters $[22,23]$. The complex effect of these factors during the electro erosion process causes geometric deviations [24] from the nominal shape, with the predominant influence being that of the technological equipment [25]. The following Tab. 1 shows the most common causes of geometric deviations of the actual machined area from the nominal. These concern the machine tool, the tool [26], the workpiece and the settings of the process and technological parameters.

This report in Tab. 1 shows that, when machining curved surfaces and in particular circular cross sections by WEDM technology, the decisive factor is the precise software feeding of the wire electrode along the circular path.
Table 1 The most common causes of geometric deviations of the real shape from the nominal machined surface with the wire tool electrode WEDM

\begin{tabular}{|c|c|}
\hline Influencing factor & $\begin{array}{l}\text { Reasons for geometric deviations of shape of } \\
\text { machined surface }\end{array}$ \\
\hline $\begin{array}{l}\text { Machining } \mathrm{CNC} \\
\text { electro-erosion } \\
\text { machine }\end{array}$ & $\begin{array}{l}\text { - major and minor axis conduction errors, } \\
\text { - wrong setting, } \\
\text { - vibration of carrier parts, } \\
\text { - elastic deformations of individual parts. }\end{array}$ \\
\hline Wire tool electrode & $\begin{array}{c}\text { - size and intensity of wear, } \\
\text { - chemical and mechanical properties of the } \\
\text { material used, } \\
\text { - diameter and composition, } \\
\text { - vibration, } \\
\text { - software management. }\end{array}$ \\
\hline Machined material & $\begin{array}{c}\text { - releasing internal residual stresses in the } \\
\text { material, } \\
\text { - shrinkage of the workpiece after electro- } \\
\text { erosive machining, } \\
\text { - chemical inhomogeneity of the material, } \\
\text { - internal disruptions or impurities in the } \\
\text { material, } \\
\text { - thermal influence of the surface layers or base } \\
\text { material, } \\
\text { - corrosion and aging of the material. }\end{array}$ \\
\hline $\begin{array}{l}\text { Setting of process } \\
\text { and technological } \\
\text { parameters }\end{array}$ & $\begin{array}{l}\text { - dielectric properties ( } \mathrm{pH} \text {, temperature, } \\
\text { electrical conductivity, purity, etc.) } \\
\text { - intensity of flushing with dielectric fluid, } \\
\text { - combination of the main technological } \\
\text { parameters.. }\end{array}$ \\
\hline
\end{tabular}

\section{MEASUREMENT OF GEOMETRIC DEVIATIONS OF CIRCULARITY OF MACHINED SURFACE}

To measure the geometrical deviations of circularity of the machined surface [27], different measuring instruments [28] and devices are used in practice. The simplest ones include templates, tooling plates and the like. However, it is necessary to emphasize that these are not very effective measuring devices. A more effective way of measuring geometric deviations of circularity of a machined surface is by means of measuring instruments, such as dial deviation meters, pasameters or 3D measuring instruments. Two basic principles are currently used to measure geometric shape deviations. In the first case, it is a measure of base-dependent geometric deviations, in the second case, the least squares for the line and for the circle (LSC) method. Measurement of base-dependent geometric deviations is generally costly and time-consuming. The individual measurement methods are described in STN ISO 6318. The simplest, but less accurate is the one, two and three-point method of circularity measurement. In onepoint measurement, it is essentially a measurement of the deviations of the workpiece diametrically with the deviation meter, with the workpiece rotating between the two points.

The maximum deviation of circularity $y_{\mathrm{Cmax}}$ is then determined as the difference between the maximum and the minimum measured value by the deviation meter according to the Eq. (1):

$y_{\mathrm{Cmax}}=y_{\max }-y_{\min }, \mu \mathrm{m}$

where:

$y_{\text {Cmax }}-\max$. deviation of circularity / $\mu \mathrm{m}$

$y_{\max }-$ max. measured value of deviation / $\mu \mathrm{m}$

$y_{\min }-\min$. measured value of deviation $/ \mu \mathrm{m}$ 
The two-point measurement measures the diameters of the workpieces circumferentially by simple two-touch measuring instruments. The maximum circle deviation $y_{\text {Cmax }}$ is then determined as the half value of the difference between the maximum and minimum measured diameter of the workpiece with the following Eq. (2):

$y_{\mathrm{Cmax}}=\frac{\max \left|\varphi_{\mathrm{D} 1}-\varphi_{\mathrm{D} 2}\right|}{2} \cdot 10^{3}, \mu \mathrm{m}$

where:

$y_{\text {Cmax }}$ - max. deviation of circularity / $\mu \mathrm{m}$

$\varphi_{\mathrm{D} 1}$ - first measured value of the workpiece diameter $/ \mathrm{mm}$ $\varphi_{\mathrm{D} 2}-$ second measured value of the workpiece diameter / $\mathrm{mm}$

The three-point method uses dial deviation meters. The measurement is performed on a prismatic pad with the measured workpiece rotating around its axis. The maximum deviation of circularity is then determined as the value of the difference between the maximum and minimum value measured by the deviation meter with the use of the Eq. (1).

As mentioned above, these methods of measuring circularity deviations are rather inaccurate [19] and serve mostly as an informative measurement. At present, the most accurate methods for measuring circularity include those that use special touch measuring devices. These include, in particular, universal coordinate systems in which the measuring touch moves around a firmly held component. Alternatively, systems are also used in which the component rotates about its axis of rotation. In this case, the deviations are detected by a special stylus. In certain specific cases, profilometer with diamond sensor or surface scanners are also used to measure circularity deviations.

\section{MATERIALS AND METHOD}

\subsection{Used Material and Methods of Work}

Experimental samples were made of fine-grained construction steel EN S355J0 for welding. It is a steel that is often used in practice on machine parts [6], cars, and so on. Its chemical composition is shown in the following Tab. 2.

Table 2 Chemical composition of EN S355J0 stee

\begin{tabular}{|c|c|c|c|c|c|c|}
\hline \multicolumn{7}{|c|}{ Chemical composition of EN S355J0 steel } \\
\hline $\mathrm{C} / \%$ & $\mathrm{Si} / \%$ & $\begin{array}{c}\mathrm{Mn} \\
/ \%\end{array}$ & $\begin{array}{c}\mathrm{P}_{\max } \\
/ \%\end{array}$ & $\begin{array}{c}\mathrm{S}_{\max } \\
/ \%\end{array}$ & $\begin{array}{c}\mathrm{N}_{\max } \\
/ \%\end{array}$ & $\begin{array}{c}\mathrm{Cu}_{\max } \\
/ \%\end{array}$ \\
\hline $\max .0 .20$ & $\max 0.55$ & 1.60 & 0.040 & 0.045 & 0.012 & 0.55 \\
\hline
\end{tabular}

The preparation of experimental samples of a circular cross-section with nominal dimensions $\phi_{\mathrm{W}}=10,20,30,40$, 60 and $80 \mathrm{~mm}$ was carried out using $\mathrm{CNC}$ electro-erosion equipment FANUC ALFA C600iA (Fig. 3).

To measure the deviations of the circularity $y_{\mathrm{Cmax}}$ of the machined surface after WEDM of the experimentally prepared samples from EN S355J0 steel, the compact MittestoyRoundtest RA-120 measuring instrument was used (Fig. 4).

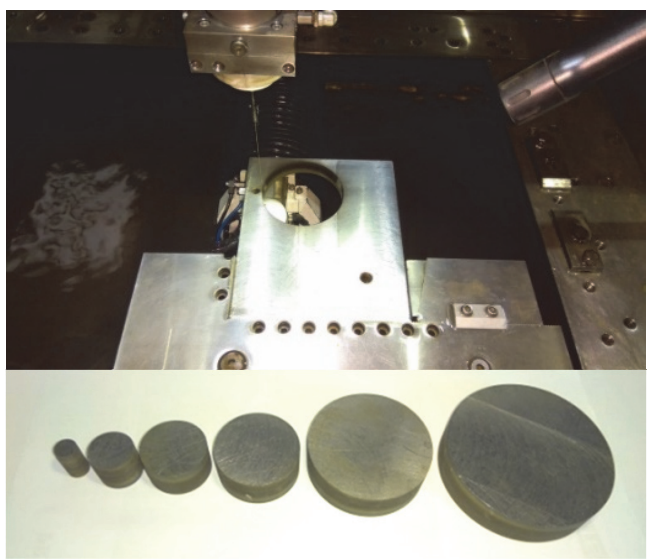

Figure 3 Preparation of experimental samples with $\phi_{N}=10,20,30,40,60$ and $80 \mathrm{~mm}$ using CNC electro-erosion equipment FANUC ALFA C600iA

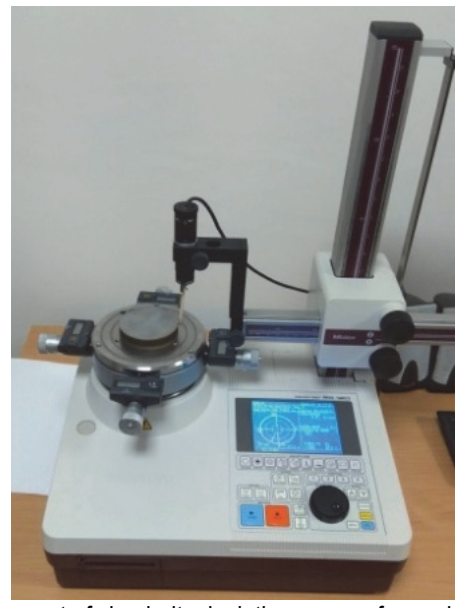

Figure 4 Measurement of circularity deviations $y_{\mathrm{Cmax}}$ of experimentally prepared samples using compact MittestoyRoundtest RA-120 measuring instrument

With this method of measuring the circularity deviations of experimentally prepared samples, a method was used in which the measured component rotated around its own axis of rotation. Continuous course of circularity deviations was scanned by a special touch tip. Measurement was performed at three levels (upper, middle and lower). The course of the measurement is shown in Fig. 5 .

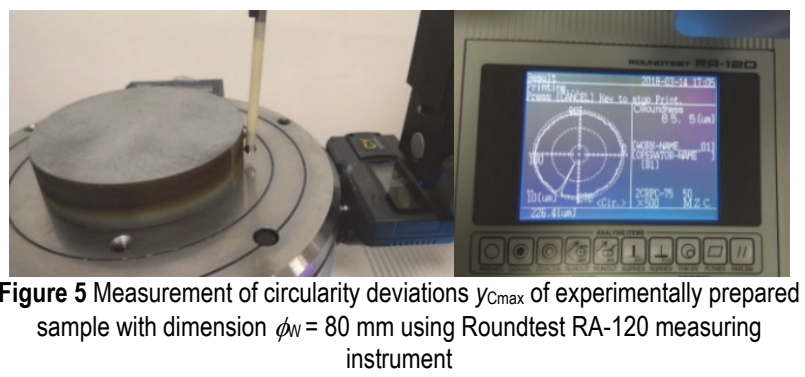

Unlike single and multipoint measurement methods using simple measuring instruments, it is much more difficult to evaluate the measured data using special touch measuring instruments. In order to evaluate the maximum deviation of circularity, it is necessary to have the "real" surface data, i.e. profile with a filtered component of roughness and waviness and a nominal "prescribed" surface. The rotation object profile is most often obtained in the form of polar diagrams. The basic requirement for correctly evaluating the deviation of circularity is therefore 
the choice of the appropriate evaluation method. Methods of evaluation of circularity deviations are given in STN ISO 4291 or STN ISO 4292.

According to the standards mentioned, the circularity deviation can be measured from any of the following centres:

a) Least Squares mean Circle (LSC), which is the circle for which the sum of squares of the deviations of this circle from the removed or modified profile of the components is the smallest.

b) Minimum Zone Circles (MZC) describes two concentric circles surrounding the removed or modified profile and have the smallest radial distance.

c) Minimum Circumscribed Circle (MCC), which is the smallest circle that can be drawn around the removed or modified profile. (Used to measure circularity deviations on the outer surface).

d) Maximum Inscribed Circle (MIC) describes the largest circle that can be drawn into the removed or modified profile. (This method is used to measure roundness deviations on the inner surface).

\section{EXPERIMENTAL EXECUTION AND RESULTS}

When evaluating the geometric deviations of circularity of $y_{C \max }$ of the machined surface of the experimentally prepared samples with nominal dimensions $\phi_{\mathrm{W}}=10.0,20.0,30.0,40.0,60.0$ and $80.0 \mathrm{~mm}$ using the progressive WEDM technology, the evaluation method according to STN ISO 4291 was used, i.e. Minimum Zone Circles (MZC). The measured data are shown in Tab. 3.

Table 3 Measured data of maximum $y_{C_{\max }}$ and average $y_{\mathrm{kp}}$ values of geometric

\begin{tabular}{|c|c|c|c|c|c|}
\hline $\begin{array}{l}\text { Rated } \\
\text { size } \\
\phi_{\mathrm{W}} / \\
\mathrm{mm}\end{array}$ & $\begin{array}{c}\text { Measured } \\
\text { location }\end{array}$ & $\begin{array}{c}\text { Measured } \\
\text { value } \\
\phi_{\mathrm{Wm}} / \mathrm{mm}\end{array}$ & $\begin{array}{l}\text { Average } \\
\text { measured } \\
\text { value } \\
\phi_{\mathrm{wp}} / \mathrm{mm}\end{array}$ & $\begin{array}{l}\text { Measured } \\
\text { value max. } \\
\text { deviations of } \\
\text { circularity } \\
y_{\text {Cmax }} / \mu \mathrm{m}\end{array}$ & $\begin{array}{c}\text { Average } \\
\text { value } \\
\text { deviation } \\
\text { of profile } \\
\text { circularity } \\
y_{\mathrm{Cp}} / \mu \mathrm{m}\end{array}$ \\
\hline \multirow{3}{*}{10.0} & upper & 9.884 & \multirow{3}{*}{9.923} & 134.70 & \multirow{3}{*}{164.37} \\
\hline & middle & 9.930 & & 190.40 & \\
\hline & lower & 9.956 & & 168.00 & \\
\hline \multirow{3}{*}{20.0} & upper & 19.965 & \multirow{3}{*}{19.896} & 114.80 & \multirow{3}{*}{136.83} \\
\hline & middle & 19.895 & & 161.70 & \\
\hline & lower & 19.826 & & 134.00 & \\
\hline \multirow{3}{*}{30.0} & upper & 29.971 & \multirow{3}{*}{29.898} & 100.40 & \multirow{3}{*}{119.70} \\
\hline & middle & 29.958 & & 141.50 & \\
\hline & lower & 29.764 & & 117.20 & \\
\hline \multirow{3}{*}{40.0} & upper & 39.901 & \multirow{3}{*}{39.918} & 90.40 & \multirow{3}{*}{105.07} \\
\hline & middle & 39.941 & & 121.90 & \\
\hline & lower & 39.911 & & 102.90 & \\
\hline \multirow{3}{*}{60.0} & upper & 59.941 & \multirow{3}{*}{59.891} & 73.60 & \multirow{3}{*}{82.40} \\
\hline & middle & 59.868 & & 93.70 & \\
\hline & lower & 59.865 & & 79.90 & \\
\hline \multirow{3}{*}{80.0} & upper & 79.914 & \multirow{3}{*}{79.935} & 66.00 & \multirow{3}{*}{74.27} \\
\hline & middle & 79.962 & & 83.60 & \\
\hline & lower & 79.930 & & 73.20 & \\
\hline
\end{tabular}

Based on the measured values of the maximum geometric deviations of circularity $y_{\mathrm{Cmax}}$ of the experimental samples of the circular cross-section with nominal dimensions $\phi_{\mathrm{W}}=10.0,20.0,30.0,40.0,60.0$ and $80.0 \mathrm{~mm}$ after WEDM with $\mathrm{CuZn} 37$ wire electrode $\phi_{\mathrm{E}}=0.25 \mathrm{~mm}$, the graphic relations shown in Fig. 6 were created.

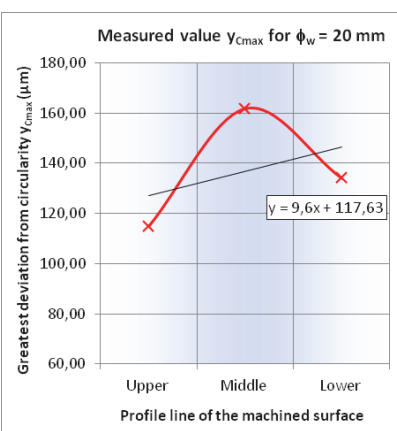

a)

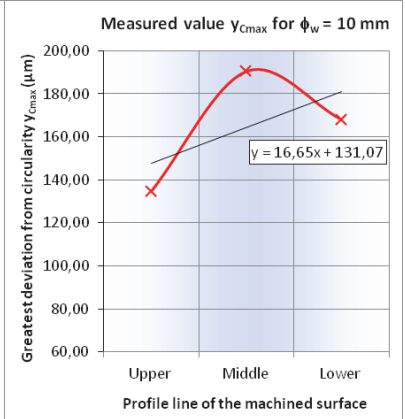

b)
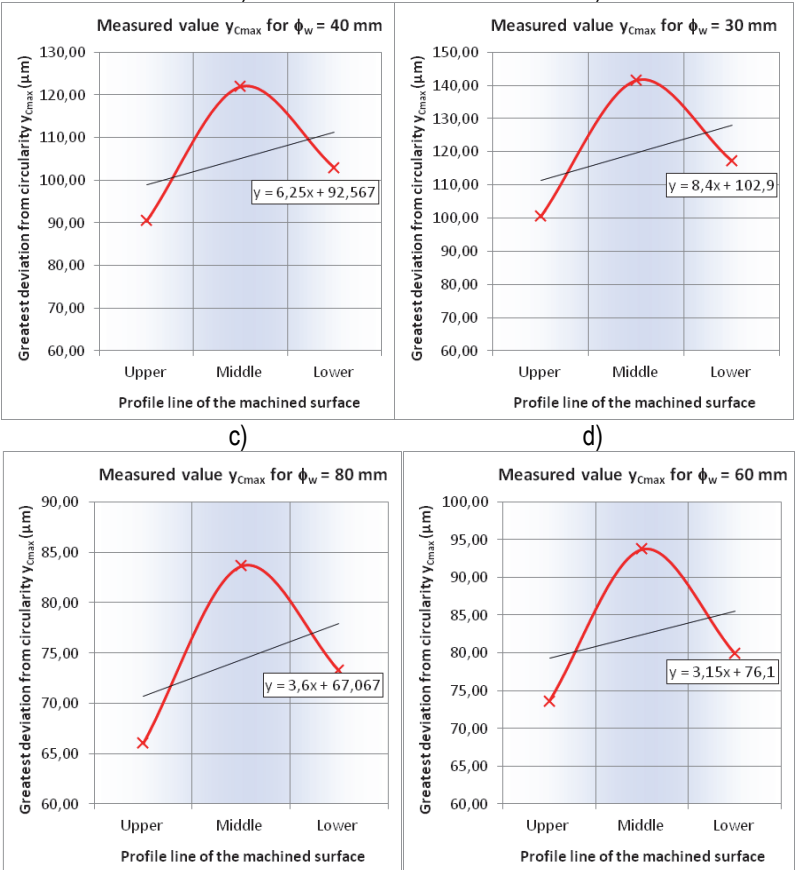

e)

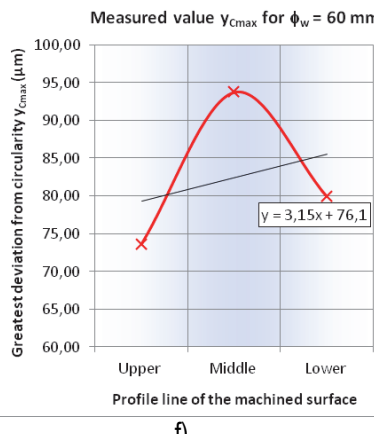

Figure 6 Geometric deviations of circularity $y_{\mathrm{Cmax}_{\text {max }}}$ of EN S355J0 steel after WEDM with CUZn37 wire electrode $\phi_{\mathrm{E}}=0.25 \mathrm{~mm}$ in upper, middle and lower profile line of the machined surface with thickness of $H \mathrm{w}=20.0 \mathrm{~mm}$

Graphical relations in Fig. 6 show the course of the values of the maximum geometric deviations of circularity $y_{\text {Cmax }}$ of the circular cross-sectional experimental samples with a nominal dimension $\phi_{\mathrm{W}}=10.0,20.0,30.0,40.0,60.0$ and $80.0 \mathrm{~mm}$ after WEDM in three profile lines (upper, middle and lower) of the machined surface with a thickness of $H_{\mathrm{w}}=20.0 \mathrm{~mm}$. From the graphs in Figs. 6a to 6f it can be observed that the value of the maximum geometric deviation of the circularity $y_{\text {Cmax }}$ in individual lines of the profile of the machined surface after WEDM with $\mathrm{CuZn} 37$ wire electrode $\phi_{\mathrm{E}}=0.25 \mathrm{~mm}$ reaches the highest values approximately in the center of the profile (for a profile with $\phi_{\mathrm{W}}=10.0 \mathrm{~mm}$ the value $\left.y_{\mathrm{C} \max }=190.4 \mu \mathrm{m}\right)$. Lower $y_{\mathrm{Cmax}}$ values were recorded at the lower line of the profile of the machined surface and the lowest values were recorded in the upper line (for a profile with $\phi_{\mathrm{W}}=80.0 \mathrm{~mm}$ the value is $\left.y_{\text {Cmax }}=66.0 \mu \mathrm{m}\right)$. This deviation of the measured $y_{\text {Cmax }}$ values between the upper and the middle line of the profile of the machined surface is 20 to $30 \%$ in the samples with nominal dimensions $\phi_{\mathrm{W}}=10.0$ to $80.0 \mathrm{~mm}$. A lower percentage deviation of the measured data was recorded at larger diameters. On the other hand it was higher for smaller cross-sections of the profile $\phi_{\mathrm{w}}$ of the machined area. 
Based on the measured values, graphical dependencies (Fig. 7) were created. These describe the course of the maximum geometric deviations of the circularity of $y_{\mathrm{Cmax}}$ of the circular cross-sectional experimental samples with nominal dimensions in the range of $\phi_{\mathrm{w}}=10.0$ to $80.0 \mathrm{~mm}$ in the individual profile lines (upper, middle and lower) of the machined surface.

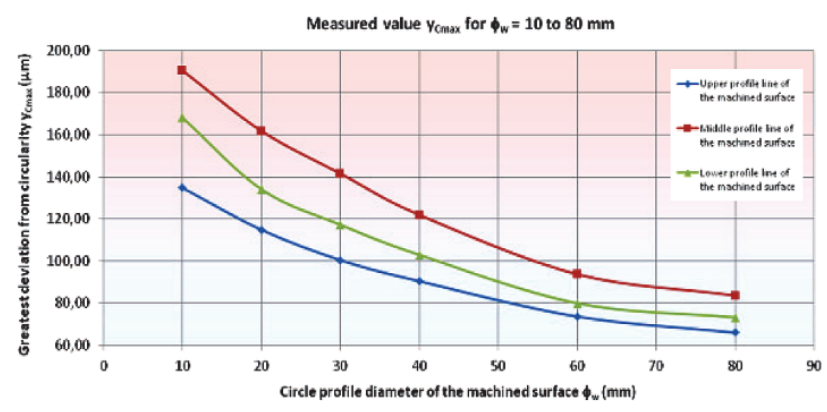

Figure 7 Maximum values of geometric circularity deviations $y_{C_{\text {max }}}$ of EN S355J0 steel after WEDM with CUZn37 wire electrode $\phi_{\mathrm{E}}=0.25 \mathrm{~mm}$ in respective profile lines of machined surface within the nominal dimensions $\phi_{w}=10.0$ to $80.0 \mathrm{~mm}$

From the graph in Fig. 7 it can be observed that the value of the maximum geometric deviation of circularity $y_{\mathrm{Cmax}}$ in individual lines of the profile of the machined surface after WEDM with the $\mathrm{CuZn} 37$ wire electrode $\phi_{\mathrm{E}}=0.25 \mathrm{~mm}$ is dependent on the diameter of the eroded surface $\phi_{\mathrm{w}}$. Furthermore, it can be observed that its size paradoxically decreases with an increasing $\phi_{\mathrm{W}}$ of the machined surface. Its maximum size for $\phi_{\mathrm{W}}$ of the machined surface in the range of 10.0 to $80.0 \mathrm{~mm}$ ranges at $y_{\mathrm{Cmax}}=66.0$ to $190.4 \mu \mathrm{m}$. Higher value applies to smaller $\phi_{\mathrm{W}}$ of the machined surface with the lower value applying to larger $\phi_{\mathrm{W}}$ of the machined surface. Based on the abovementioned course of the maximum values of geometric deviation of circularity $y_{\mathrm{Kmax}}$ in the individual machined surface profile lines, it can be seen that in the range of $\phi_{\mathrm{W}}$ $=10.0$ to $80.0 \mathrm{~mm}$ the higher values were recorded in the middle part of the machined surface profile. In contrast, the smallest $y_{\text {Cmax }}$ values were recorded in the upper line of the profile of the machined surface. With detail examination of the possible causes, we have come to the conclusion that this deviation could have been caused by a higher pollution of the dielectric fluid in the middle line compared to the upper and lower line of the profile of the machined surface.

Another supposed reason for the higher geometric deviation of circularity $y_{\mathrm{Cmax}}$ in the middle line compared to the upper and lower line of the profile of the machined surface is seen in the presence of vibrations in feeding of the wire electrode. Despite the tensioning of the wire electrode with a tension force approaching the maximum values appropriate for the given strength of the wire electrode material, it was not possible to completely eliminate the vibrations [29] that are generated by the shocks [30] between the electrode and the material to be machined [31]. These achieve maximum amplitude approximately at the centre of the profile of the machined surface, as confirmed by the individual recorded values of the maximum geometric deviations of circularity in this area.

Higher values of deviations of the geometric accuracy of the eroded surface in the middle part of the workpiece compared to the edge parts are also the reason for the inappropriate choice of the combination of technological and process parameters. These are especially pronounced at larger thicknesses of the machined material. The material properties of the workpiece and the tool electrode also play an important role in this regard. Therefore, further research is needed in this area.

\section{CONCLUSION}

In practice, a great deal of emphasis is often placed on qualitative indicators [32-34] in terms of roughness parameters of machined surface. At the same time, the geometric deviations of the machined surface have a primary impact on the operational functionality, durability, and operating life of WEDM manufactured products by progressive technology $[35,36]$. For these reasons, experimental research was conducted focusing on the determination of the maximum circularity deviation $y_{\mathrm{Cmax}}$ during the manufacturing of parts from EN S355J0 steel using WEDM with $\mathrm{CuZn} 37$ wire electrode $\phi_{\mathrm{E}}=0.25 \mathrm{~mm}$. In case of WEDM the experimental research actually showed the presence of geometrical inaccuracies in shape of the machined surface in terms of deviation of circularity. These varied quantitatively depending on the size of the actual dimension $\phi_{\mathrm{W}}$ of the machined surface of the circular profile. The increasing trend of maximum deviation of circularity $y_{\mathrm{Cmax}}$ was recorded with decreasing $\phi_{\mathrm{W}}$ of the machined surface.

Summary of experimental research results:

- Based on the results of the experimental research, the maximum deviations of the circularity of the machined surface $y_{\mathrm{Cmax}}$ for the individual dimensions $\phi_{\mathrm{W}}=10.0$, 20.0, 30.0, 40.0, 60.0 and $80.0 \mathrm{~mm}$ with the thickness of the machined material $H_{\mathrm{w}}=20.0 \mathrm{~mm}$ were identified.

- It was determined that the values of the maximum geometric deviations of circularity $y_{\mathrm{Cmax}}$ are different not only for the individual $\phi_{\mathrm{W}}$ diameters, but also for the individual lines of the profile of the machined surface.

- For the size range of the machined surface $\phi_{\mathrm{W}}=10.0$ to $80.0 \mathrm{~mm}$, the maximum deviations of the circularity $y_{\text {Cmax }}$ of the machined surface at the level of 66.0 to $190.4 \mu \mathrm{m}$ were recorded.

- At the same time it was found that the maximum deviations of circularity $y_{\text {Cmax }}$ of the machined surface reach the highest values approximately in the center of the profile (for the profile with $\phi_{\mathrm{W}}=10.0 \mathrm{~mm}$ the value is $\left.y_{\mathrm{Cmax}}=190.4 \mu \mathrm{m}\right)$ and the lowest values in the upper line (for profile $\phi_{\mathrm{W}}=80.0 \mathrm{~mm}$ the value is $y_{\mathrm{Cmax}}=66.0$ $\mu \mathrm{m})$.

- Deviation of the measured $y_{\mathrm{Cmax}}$ values between the upper and intermediate line of the profile of the machined surface in samples with nominal dimensions $\phi_{\mathrm{W}}=10.0$ to $80.0 \mathrm{~mm}$ at $20-30 \%$ was identified.

- Experimental research was oriented with regard to the practical use of the results achieved not only for theory but also for technical practice. The results obtained in terms of identifying the maximum deviations of the circularity $y_{\text {Cmax }}$ of the machined surface after WEDM thus enable meeting much narrower specifications of the requirements for the workpiece quality. 


\section{Acknowledgements}

The authors would like to thank the grant agency for supporting research work of the project VEGA 1/0205/19.

\section{REFERENCES}

[1] Mouralova, K., Zahradnicek, R., \& Houska, P. (2016). Evaluation of surface quality of X210Cr12 steel for forming tools machined by WEDM. MM Science Journal, 2016(5), 1366-1369. https://doi.org/ 10.17973/MMSJ.2016_11_2016123

[2] Wang, X. (2017). An experimental study of the effect of ultrasonic vibration assisted wire sawing on surface roughness of $\mathrm{SiC}$ single crystal. Academic Journal of Manufacturing Engineering, 15(4), 6-12.

[3] Ali, M. et al. (2018). Dimensional Accuracy in Dry Micro Wire Electrical Discharge Machining. Journal of Mechanical Engineering and Sciences, 12(1), 3321-3329. https://doi.org/10.15282/jmes.12.1.2018.4.0298

[4] Firouzabadi, H. A., Parvizian, J., \& Abdullah, A. (2015). Improving accuracy of curved corners in wire EDM successive cutting. International Journal of Advanced Manufacturing Technology, 76, 447-459. https://doi.org/10.1007/s00170-014-6270-0

[5] Islam, M. N., Rafai, N. H., \& Subramanian, S. S. (2010). An Investigation into Dimensional Accuracy Achievable in Wire-cut Electrical Discharge Machining. Proceedings of the World Congress on Engineering, WCE 2010, 1-6.

[6] Raksiri, C. H. \& Chatchaikulsiri, P. (2010). CNC Wire-Cut Parameter Optimized Determination of the Stair Shape Workpiece. International Journal of Mechanical and Mechatronics Engineering, 4(10), 924-929. https://doi.org/ doi.org/10.5281/zenodo.1073331

[7] Sanchez, J. A. et al. (2007). On the influence of cutting speed limitation on the accuracy of wire-EDM corner-cutting. Journal of Materials Processing Technology, 182(1-2), 574579. https://doi.org/10.1016/j.jmatprotec.2006.09.030

[8] Yan, M. T., Wang, P. W., \& Lai, J. C. H. (2016) Improvement of part straightness accuracy in rough cutting of wire EDM through a mechatronic system design. International Journal of Advanced Manufacturing Technology, 84, 2623-2635.

[9] Zhang, W. \& Wang, X. (2017). Simulation of the inventory cost for rotable spare with fleet size impact. Academic Journal of Manufacturing Engineering, 15(4), 124-132.

[10] Mahdieh, M. S. \& Zare-Reisabadi, S. (2019). Effects of electro-discharge machining process on ultra-fined grain copper. Proceedings of the Institution of Mechanical Engineers, Part C: Journal of Mechanical Engineering Science, 233(15), 5341-5349. https://doi.org/10.1177/0954406219844802

[11] Puri, A. B. \& Bhattacharyya, B. (2003). An analysis and optimization of the geometrical in accuracy due to wire lag phenomenon in WEDM. International Journal of Machine Tools and Manufacture, 43, 151-159. https://doi.org/10.1016/S0890-6955\%2802\%2900158-X

[12] Krsek, A. \& Bachratý, M. (2008). Fundamentals of quality control of geometric component parameters. FX s.r.o., Bratislava.

[13] Čorný, I., Fedák, M., \& Rimár, M. (2014). Chilled Ceiling Adaptive Control with Application of Parameters Gained from the Chilled Ceiling System Proposal Algorithm. Applied Mechanics and Materials, 616, 317-324. https://doi.org/10.4028/www.scientific.net/AMM.616.317

[14] Panda, A., Prislupčák, M., \& Pandová, I. (2014). Progressive technology diagnostic and factors affecting to machinability. Applied Mechanics and Materials, 616, 183-190. https://doi.org/10.4028/www.scientific.net/AMM.616.183
[15] Žitňanský, J., Žarnovský, J., \& Ružbarský, J. (2013). Analysis of physical effects in cutting machining. Advanced Materials Research, 801, 51-59. https://doi.org/10.4028/www.scientific.net/AMR.801.51

[16] Čorný, I. (2017). Overview of progressive evaluation methods for monitoring of heat production and distribution. Procedia Engineering, 190, 619-626. https://doi.org/10.1016/j.proeng.2017.05.388

[17] Botko, F. et al. (2018). Determination of CVD coating thickness for shaped surface tool. TEM Journal, 7(2), 428432. https://dx.doi.org/10.18421/TEM72-26

[18] Baron, P., Zajac, J., \& Pollák, M. (2016). The correlation of parameters measured on rotary machine after reparation of disrepair state. MM Science Journal, 2016(11), 1244-1248. https://doi.org./10.17973/MMSJ.2016_11_201667

[19] Pandová, I., Oravec, P., \& Matisková, D. (2017). Sorption Characteristics of cooper sorption on the clinoptilolite measurement. MM Science Journal, 2017(12), 1977-1980. https://doi.org./10.17973/MMSJ.2017_12_201749

[20] Venkatarao, K. \& Kumar, T. A. (2019). An experimental parametric analysis on performance characteristics in wire electric discharge machining of Inconel 718. Proceedings of the Institution of Mechanical Engineers, Part C: Journal of Mechanical Engineering Science, 233(14), 48364849. https://doi.org/10.1177\%2F0954406219840677

[21] Yan, S. et al. (2018). Study on point bar residual oil distribution based on dense well pattern in Sazhong area. Journal of Mines, Metals and Fuels, 65(12), 743-748.

[22] Salcedo, A. T., Arbizu, P. I., \& Perez, C. J. L. (2017). Analytical modelling of energy density and optimization of the EDM machining parameters of inconel 600. Metals, 7(5), 166. https://doi.org/10.3390/met7050166

[23] Straka, L. et al. (2017). Statistical Approach to Optimize the Process Parameters of HAZ of Tool Steel EN X32CrMoV12-28 after Die-Sinking EDM with SF-Cu Electrode. Metals, 7(2), 1-22. https://doi.org/10.3390/met7020035

[24] Świercz, R. \& Oniszczuk-Świercz, D. (2017). Experimental Investigation of Surface Layer Properties of High Thermal Conductivity Tool Steel after Electrical Discharge Machining. Metals, 7(12), 550. https://doi.org/10.3390/met7120550

[25] Hašová, S. \& Straka, L. (2016). Design and verification of software for simulation of selected quality indicators of machined surface after WEDM. Academic Journal of Manufacturing Engineering, 14(2), 13-20.

[26] Huang, H. et al. (2017). Measuring and presetting system for tool electrodes used for machining rimmed turbine blisks. Transactions of the Institute of Measurement and Control, 39(9), 1421-1430. https://doi.org/10.1177\%2F0142331216640872

[27] Mičietová, A., Neslušan, M., \& Čilliková, M. (2013). Influence of surface geometry and structure after nonconventional methods of parting on the following milling operations. Manufacturing Technology, 13, 199-204. https://doi.org/10.21062/ujep/x.2013/a/1213-2489/MT/13/2/199

[28] Sahu, S. K. \& Datta, S. (2019). Experimental studies on graphite powder-mixed electro-discharge machining of Inconel 718 super alloys: Comparison with conventional electro-dischargemachining. Proceedings of the Institution of Mechanical Engineers, Part E: Journal of Process Mechanical Engineering, 233(2), 384-402. https://doi.org/10.1177\%2F0954408918787104

[29] Olejárová, Š., Dobránsky, J., \& Panda, A. (2017). Monitoring the intensity of mechanical vibration during the processing of chrome steel 14109. Metalurgija, 56(1-2), $164-166$. 
[30] Straka, L', Čorný, I. \& Pitel', J. (2016). Properties evaluation of thin microhardened surface layer of tool steel after wire EDM. Metals, 6(5), 1-16. https://doi.org/10.3390/met6050095

[31] Fedák, M. et al. (2013) Experimental Study of Correlation of Mechanical Properties of Al-Si Casts Produced by Pressure Die Casting with SiFeMn Content and Their Mutual Mass Relations. Advances in Materials Science and Engineering, 2013, 1-7. https://doi.org/10.1155/2013/585714

[32] Straka, L. \& Hašová, S. (2016). Prediction of the heataffected zone of tool steel EN X37CrMoV5-1 after diesinking electrical discharge machining. Proceedings of the Institution of Mechanical Engineers, Part E: Journal of Process Mechanical Engineering, 9, 1-12. https://doi.org/10.1177\%2F0954405416667405

[33] Ťavodová, M. (2014). Research state heat affected zone of the material after wire EDM. Acta Facultatis Technicae, 19, 145-152.

[34] Dubják, J., Pitel', J., \& Tóthová, M. (2016). Diagnostics of aluminum alloys melting temperature in high pressure casting. Key Engineering Materials, 669, 110-117. https://doi.org/10.4028/www.scientific.net/KEM.669.110

[35] Prislupčák, M. et al. (2014). Diagnostic and experimental valuation on progressive machining unit. Applied Mechanics and Materials, 616, 191-199.

https://doi.org/10.4028/www.scientific.net/AMM.616.191

[36] Straka, L. (2014).Analysis of Wire-Cut Electrical Discharge Machined Surface. LAP Lambert Academic Publishing.

\section{Contact information:}

L'uboslav STRAKA, Assoc., Prof., Ing., PhD

(Corresponding author)

Faculty of Manufacturing Technologies of the Technical University of Košice with a seat in Prešov, Department of Automobile and Manufacturing Technologies,

Štúrova 31, 08001 Prešov, Slovakia

E-mail: luboslav.straka@tuke.sk

Ján PITEL', Assoc., Prof., Ing., PhD

Faculty of Manufacturing Technologies of the Technical University of Košice with a seat in Prešov, Department of Industrial Engineering and Informatics,

Bayerova 1, 08001 Prešov, Slovakia

E-mail: jan.pitel@tuke.sk

Peter MICHALÍK, Assoc., Prof., Ing., PhD

Faculty of Manufacturing Technologies of the Technical University of Košice with a seat in Prešov, Department of Automobile and Manufacturing Technologies

Štúrova 31, 08001 Prešov, Slovakia

E-mail: peter.michalik@tuke.sk 